\title{
Experimental Investigation on the Compaction and Compressible Properties of Expansive Soil Reinforced with Bagasse Fibre and Lime
}

\author{
Liet Chi Dang ${ }^{1}$ and Hadi Khabbaz ${ }^{2}$
}

\author{
${ }^{1}$ Ph.D., School of Civil and Environmental Engineering, University of Technology Sydney (UTS), 15 \\ Broadway, Ultimo, NSW 2007, Australia; e-mail: liet.dang@uts.edu.au. \\ ${ }^{2}$ Associate Professor, School of Civil and Environmental Engineering, University of Technology \\ Sydney (UTS), 15 Broadway, Ultimo, NSW 2007, Australia; e-mail: hadi.khabbaz@uts.edu.au.
}

\begin{abstract}
This paper presents a laboratory investigation into the mechanical characteristics of expansive soil reinforced with randomly distributed bagasse fibre and lime combination. Bagasse fibre, an agricultural waste by-product left after crushing of sugar-cane for juice extraction, was employed in this investigation as a reinforcing component for expansive soil reinforcement. Several series of laboratory experiments including standard compaction and consolidation tests were carried out on untreated soil and soil samples mixed with various contents of bagasse fibre in a wide range from $0 \%$ to $2 \%$ and a certain amount of $2.5 \%$ lime. The experimental results were used to comprehend the effects of adding bagasse fibre on the compaction and compressible properties of fibre reinforced soils with lime stabilisation. The compaction test results indicate that the addition of bagasse fibre, hydrated lime, and their combination decreased the dry density of stabilised soils. Moreover, the obtained results of the consolidation tests reveal that the reinforcement of expansive soil with bagasse fibre improved the pre-consolidation pressure, meanwhile tended to reduce the compression characteristics of the lime stabilised soils as bagasse fibre content increased from $0 \%$ to $1 \%$. However, an excessive increase in bagasse fibre content beyond $1 \%$ to $2 \%$ was found to result in a slight reduction of the compressibility of lime-soil mixtures reinforced with bagasse fibre. The findings of this research provide a deeper insight into promoting applications of an agricultural waste by-product of bagasse fibre as a lowcost and eco-friendly material for treatment of expansive soils and fill materials for sustainable construction development in the field of civil infrastructure foundations.
\end{abstract}

\section{INTRODUCTION}

Expansive soils are fine-grained soil or decomposed rocks, showing significant volume change when exposed to variations of moisture content. Swelling and shrinkage behaviour is most likely to take place near the ground surface where it is directly prone to environmental and seasonal fluctuations. The expansive soils are usually at unsaturated state and have dominantly montmorillonite clay minerals. Most of the severe damage to residential buildings and other civil engineering structures built on top of expansive soils is dependent on the amount of monovalent cations absorbed into clay minerals. The average annual cost of damage to structures due to shrinkage and swelling is estimated about $£ 400$ million in the UK, $\$ 15$ billion in the USA, and many billions of dollars worldwide (Jones \& Jefferson 2012).

Stabilisation of expansive soil using chemical stabilisers (e.g. lime or cement) is commonly used as the most effective improvement method to overcome the adverse 
impacts of shrinkage and expansion behaviour of expansive soil because of its volume change again moisture variation. When lime is added into expansive soil, some physical and chemical changes between lime and expansive clay particles taking place in the presence of water alter the physico-chemical properties of expansive soil, which in turn changes the engineering characteristics of stabilised soil (Bell 1996; Dang et al. 2016c). Moreover, according to many researchers (Anggraini et al. 2016; Dang 2018; Dang et al. 2015a; Dang et al. 2015b; Dang \& Khabbaz 2018a, 2018b, 2018c; Dang et al. 2017b; Fatahi \& Khabbaz 2013, 2015; Fatahi et al. 2012; Kampala \& Horpibulsuk 2013), soil stabilisation using lime or cement combined with waste by-products (fly ash, bagasse ash, rice husk ash, coconut coir fibre, recycled carpet fibre and bagasse fibre, just to name a few) can extend the effectiveness of lime stabilisation of clayey soils in terms of compressive strength, shear strength, permeability, and ductility. Thus, the utilisation of combined lime and waste by-products was identified as an eco-friendly alternative solution in improving the engineering properties of clay expansive soils and it has increasingly become an extensive research interest in recent years. Moreover, it is interesting to state that as well-documented in the literature, lime stabilisation of clay expansive soil with fibre reinforcement can be used as an alternative earth load transfer platform in support of highway and railway embankments constructed on columns improved soft grounds (Dang et al. 2016a; Dang et al. 2017a, 2018a, 2018b, 2018c).

The experimental investigation by Chen \& Indraratna (2014), however, indicated that conventional chemical stabilisers (e.g. lime, cement) for soil stabilisation are not always acceptable in Australia since they may cause adverse effects on the environment by changing the $\mathrm{pH}$ level of treated soil and its surrounding areas. As a result, the quality of ground-water and the normal growth of vegetation can be affected because of the $\mathrm{pH}$ change. On top on that, the increasing use of conventional chemical agents to stabilise soil can produce high compressive strength, but also increase the brittleness behaviour of stabilised soil, which influences the soil stability when subjected to cyclic traffic loading under road and railway embankments. Therefore, an environmentally friendly alternative solution such as bagasse fibre reinforcement of soils combined with lime stabilisation is necessary to improve the strength, the ductility and the durability of stabilised soils, meanwhile minimises the negative effects on the environment.

Recently, Dang et al. (2016b) examined the performance of bagasse fibre in enhancing the linear shrinkage and the compressive strength of compacted expansive soils by changing bagasse fibre content from $0 \%$ to $2 \%$ along with increasing curing time from 3 to 28 days. The test results indicated that as the curing time increased up to 7 days, the introduction of bagasse fibre reinforcement from $0 \%$ to $2 \%$ improved both the linear shrinkage and the compressive strength of expansive soil and then they remained most likely unchanged with a longer curing time. They concluded that the improvement in the shrinkage and the strength of soils reinforced with bagasse fibre might be due to the development of interaction and interlocking mechanism between fibre surface and soil matrix by compaction energy and with time. Viswanadham et al. (2009) studied the swelling behaviour of geofibre reinforced expansive soil by mixing various polypropylene fibre content from $0.25 \%$ to $0.5 \%$ and different aspect ratios of 15,30 and 45 . Based on the favourable results obtained, they concluded that polypropylene 
fibre effectively improved the heave and swelling pressure of expansive soil. The maximum reduction of the heave and the swelling pressure was found at the fibre content of $0.25 \%$ and the lower aspect ratio between 15 and 30 . According to Mohamed (2013), the shear strength and tensile strength of expansive clay soil reinforced with Hay fibre increased as the fibre content added into soil mixtures increased up to $1 \%$. Meanwhile, the shrinkage limit and the swelling potential decreased up to $1 \%$ Hay fibre insertion to the soil matrix followed by an increase with higher fibre addition up to $1.5 \%$. Although those aforementioned experimental investigations indicated that both natural and synthetic fibre could be beneficial for the engineering property improvement of expansive soil with or without chemical stabilisation as fibre content increased from $0 \%$ to $1.5 \%$. However, the influence of a combination of natural fibres such as bagasse fibre and lime for expansive soil treatment on the other engineering properties such as compaction and compressibility have not fully been investigated and well reported in the literature.

To have a comprehensive understanding of the potential utilisation of natural fibre for expansive soil reinforcement, several series of laboratory experiments, including standard compaction and consolidation tests, were performed on natural expansive soil and treated soil samples with different contents of randomly distributed bagasse fibre ranging from 0 and $2 \%$ and a fixed lime content after 7 days of curing and soaking. The test results of this experimental investigation are analysed and discussed to comprehend the influence of bagasse fibre reinforcement and lime stabilisation on the compaction and compression characteristics of expansive soil. It should be noted that the only results obtained from the compaction and consolidation tests are presented in this paper, which are part of an ongoing research project of characterisation and treatment of expansive soils using agricultural waste by-products (bagasse ash and fibre). Further experimental evaluations of the influence of bagasse fibre inclusions on the shrink-swell behaviour of reinforced expansive soils could be found in Dang et al. (2016b) and Dang et al. $(2017 \mathrm{c})$. Moreover, as known that natural fibre reinforcement is biodegradable with time, it is indispensable to improve the durability of natural fibre such as bagasse fibre by applying chemical treatment (i.e. sodium hydroxide, sodium silica, sodium sulphite) and/or coating (asphalt emulsion, rosin-alcohol, acrylic, polystyrene, and silane) to prevent water absorption. However, the results of those tests, which are beyond the scope of this paper, were identified as a follow-up publication.

\section{MATERIALS}

\section{Natural soil}

Soil samples collected from Queensland, Australia, was used in this experimental investigation. After removal of visible organic matters such as tree roots and leaves, the soil was air-dried and broken into pieces in the laboratory. The specific gravity of soil solids $\left(\mathrm{G}_{\mathrm{s}}\right)$ was $2.64 \pm 0.02$. The grain size distribution illustrated that there were $0.1 \%$ of particles in the range of gravel, $18.3 \%$ in the range of sand and $81.6 \%$ of fine-grained material (i.e. silt/clay). Atterberg limits of the fine-grained portion of material were about $86 \%$ liquid limit (LL) and 37\% plastic limit (PL), which yielded to a plasticity index (PI) of $49 \%$. The average linear shrinkage and natural moisture content of the samples was $21.7 \%$ and $30.8 \%$, respectively. In term of sizes of particles, the soil was 
classified as high plasticity clay $(\mathrm{CH})$ according to the Unified Soil Classification System (USCS) (AS 1993). Based on the high linear shrinkage and plasticity index, the soil can be classified as highly expansive soil.

\section{Bagasse fibre}

Bagasse fibre used in this study was obtained from ISIS Central Sugar Mill Co., Ltd, Queensland in Australia. The bagasse fibre, as depicted in FIG. 1, had a diameter ranging from $0.3 \mathrm{~mm}$ to $3.1 \mathrm{~mm}$ and a length ranging from $0.3 \mathrm{~mm}$ to $13.8 \mathrm{~mm}$. The specific gravity of bagasse fibre $\left(\mathrm{G}_{\mathrm{f}}\right)$ was about $1.25-1.55$ and their average tensile strength was $96.24 \pm 29.95 \mathrm{MPa}$. The obtained fibre was air dried in a controlled room environment with a temperature of $25^{\circ} \mathrm{C}$ and a relative humidity of $80 \%$ until its mass remained constant. Then, the dried fibres were carefully sieved and passed through 9.5 $\mathrm{mm}$ aperture sieve and retained on $300 \mu \mathrm{m}$ aperture sieve, which were selected for this investigation.

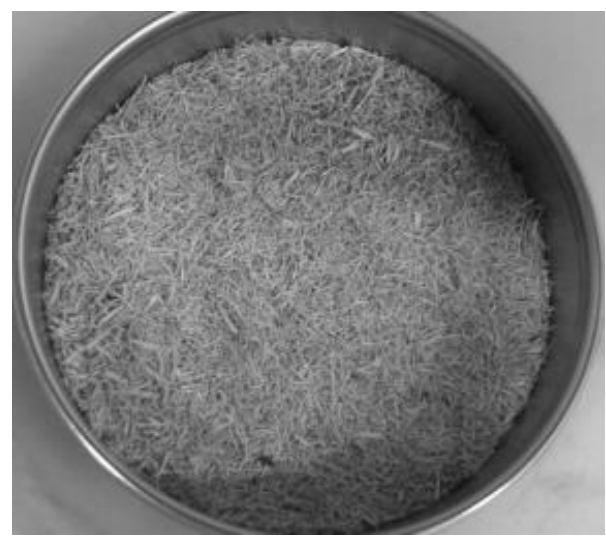

FIG. 1. Bagasse fibre used in this investigation

Table 1. Chemical composition and physical properties of hydrated lime

\begin{tabular}{lccc}
\hline \multicolumn{2}{c}{ Physical properties } & \multicolumn{2}{c}{ Chemical Composition } \\
\hline Property & Value & Components & Content (\%) \\
\hline Specific gravity & $2.2-2.3$ & Ignition loss & $24 \%$ \\
Bulk density $\left(\mathrm{kg} / \mathrm{m}^{3}\right)$ & $400-600$ & $\mathrm{SiO}_{2}$ & 1.8 \\
$\mathrm{pH}$ & 12.0 & $\mathrm{Al}_{2} \mathrm{O}_{3}$ & 0.5 \\
& & $\mathrm{Fe}_{2} \mathrm{O}_{3}$ & 0.6 \\
& & $\mathrm{CaO}$ & 72.0 \\
& & $\mathrm{MgO}$ & 1.0 \\
& & $\mathrm{CO}_{2}$ & 2.5 \\
\hline
\end{tabular}

\section{Hydrated lime}

Hydrated lime utilised in this study (FIG. 2) has about $90 \%$ of calcium hydroxide. The hydrated lime was locally purchased in Sydney. Table 1 shows the physical and chemical properties of hydrated lime provided by the producer. 


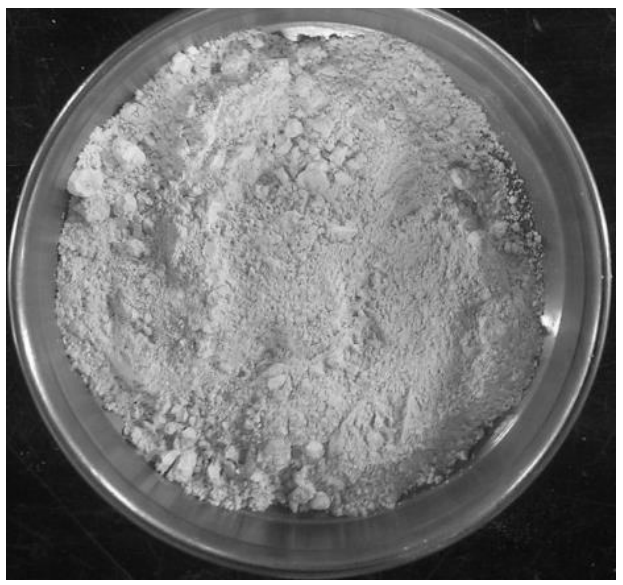

FIG. 2. Hydrated lime used in this investigation

\section{SAMPLE PREPARATION AND EXPERIMENTAL PROGRAM}

Mixing of materials

Soil samples were prepared by thoroughly mixing the pulverized natural soil with individual hydrated lime, bagasse fibre or their combination, as shown in Table 2, to become homogeneous mixtures before tap water was added at the target water content. It can be noted that in this investigation, the additive and water contents were calculated based on the total dry weight of each mixture. Following this preparation, the mixtures were mixed thoroughly using a mechanical mixer. After mixing of the materials, soil specimens (FIG. 3) were prepared for many conventional geotechnical experiments.

Table 2. Summary of mixtures employed in this investigation

\begin{tabular}{cccc}
\hline Mix No. & $\begin{array}{c}\text { Bagasse Fibre } \\
\text { content (\%) }\end{array}$ & Hydrated Lime (\%) & Notes \\
\hline 1 & 0 & 0 & Natural soil \\
\hline 2 & 0.5 & 0 & Bagasse fibre and soil \\
3 & 1.0 & 0 & \\
4 & 2.0 & 0 & \\
\hline 5 & 0.5 & 2.5 & Lime, bagasse fibre and soil \\
6 & 1.0 & 2.5 & \\
7 & 2.0 & 2.5 & \\
\hline
\end{tabular}




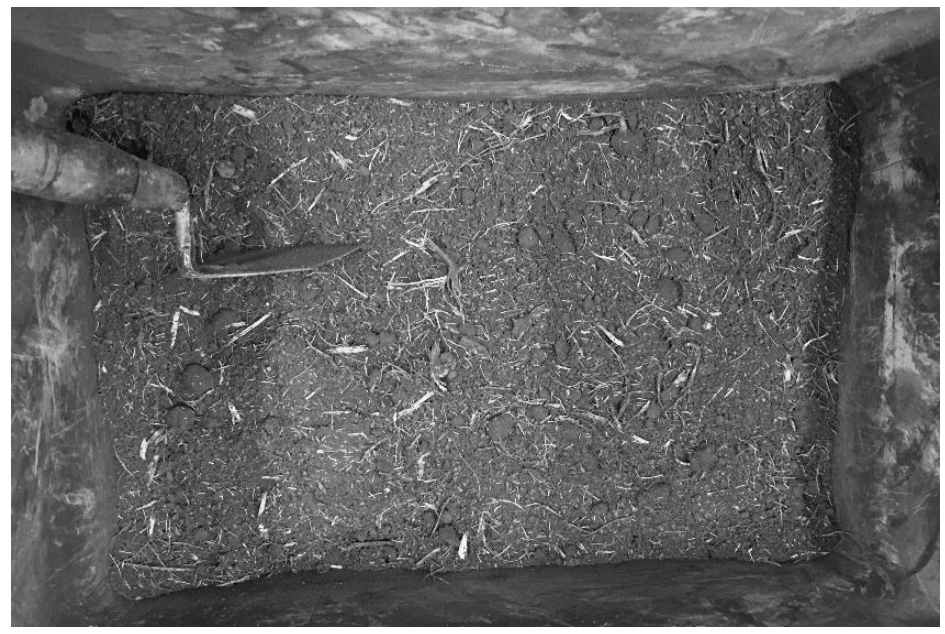

FIG. 3. Additives and soil mixing

\section{Standard Compaction Test}

Standard compaction test was carried out to determine the maximum dry density (MDD) and the optimum water content (OMC) for untreated and treated soils in accordance with the procedures prescribed in AS 1289.5.1.1 (AS 2017). Different water contents were added to the pulverised soils and thoroughly mixed to make them uniformly distributed through the soil mixtures. Then, the soil mixtures were placed in a cylindrical metal mould, with an internal diameter of $105 \mathrm{~mm}$ and height of $115.5 \mathrm{~mm}$ and compacted in three equal layers by 25 uniformly distributed blows on the rammer falling freely from a height of $300 \mathrm{~mm}$ in accordance with the procedure of AS 1289.5.1.1 (AS 2017). The specimens (FIG. 4) were extruded, measured and weighed, and their moisture contents were determined. The dry density and water content of untreated soil for each specimen were calculated and recorded in accordance with AS 1289.5.1.1 (AS 2017). A total of eleven tests on samples with different water contents were conducted to determine the MDD and the OMC of untreated soil. After that, different amounts of additives, as shown in Table 2, were added to the pulverised soil at the optimum moisture content of untreated soil. The blended mixtures were compacted in the same procedure applied to the untreated soil. The dry density of each mixture was achieved and used for carrying out other geotechnical engineering tests. 


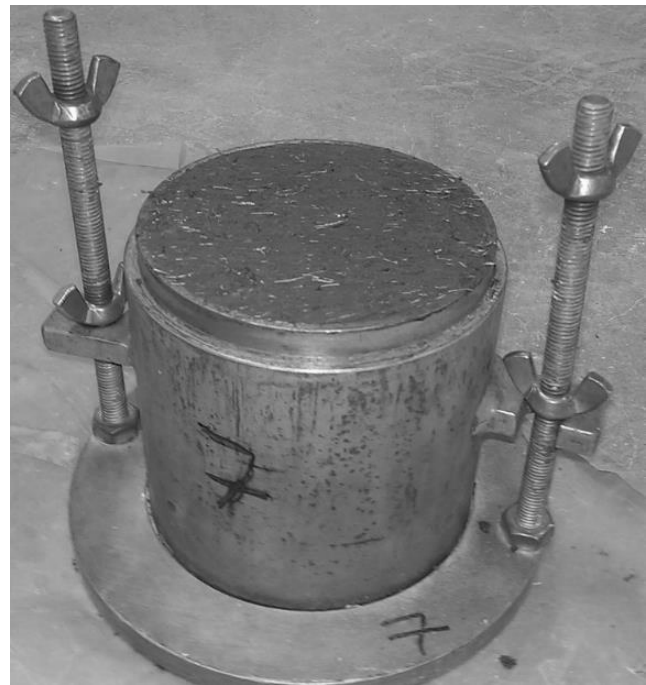

FIG. 4. Compacted soil sample

\section{One-dimensional (1D) Consolidation Tests}

A series of one-dimensional swelling consolidation tests were carried out on untreated and treated soil specimens after 3 days of curing using conventional Oedometer apparatus following the testing procedure in accordance with AS 1289.6.6.1 (AS 1998). For sample preparation, soil specimens were compacted in a cylindrical metal ring, with an internal diameter of $50 \mathrm{~mm}$ and height of $17 \mathrm{~mm}$, at the MDD and OMC. After specimen preparation and curing for 3 days, the compacted soil was extruded and put into the Oedometer ring of the same diameter and then the standard Oedometer testing setup was followed (two-way drained setup). An initial seating load of $3 \mathrm{kPa}$ was applied. Once proper loading contact was achieved, the sample was inundated with distilled water and remained for 4 days to get full saturation prior to compression. During the saturation stage of the consolidation tests, vertical swell deformations were measured using a dial gauge. After completion of this stage, the soil specimens were subjected to additional pressure incrementally in accordance with the standard consolidation test procedure AS 1289.6.6.1 (AS 1998). At any level of pressure, the applied pressure was kept on the specimens for 24 hours to ensure the completion of consolidation. For each type of mixtures, at least two samples were tested and then the average of the compression test results was presented.

\section{RESULTS AND DISCUSSION}

\section{Influence of Additive Content on Compaction Characteristics of Expansive Soil}

The standard compaction curve of untreated expansive soil as a preliminary step to determine the maximum dry density (MDD) and the optimum moisture content (OMC) of the soil only is presented in FIG. 5a. Analysis of the compaction results of natural soil found the MDD and the OMC to be $12.9 \mathrm{kN} / \mathrm{m}^{3}$ and $36.5 \%$, respectively. Subsequently, several series of soil samples mixed soils with different contents of bagasse fibre and lime were prepared at the OMC of the untreated soil (36.5\%) to investigate the influence of the additive content on the so-called maximum dry density 
of the treated soil mixtures. The obtained results of the standard compaction tests for expansive soil reinforced with various contents of bagasse fibre reinforcement and lime are depicted in FIG. 5b. It is observed that with inclusion of bagasse fibre into soils without lime treatment, the MDD of the reinforced soil mixtures gradually decreased from $12.9 \mathrm{kN} / \mathrm{m}^{3}$ to $11.4 \mathrm{kN} / \mathrm{m}^{3}$ as bagasse fibre content increased from $0 \%$ to $2 \%$. The MDD reduction could be due to the lower specific gravity of bagasse fibre in comparison with that of untreated soil. Furthermore, addition of $2.5 \%$ hydrated lime into bagasse fibre reinforced soil mixtures as observed in FIG. 5b shows that the MDD of stabilised soils decreased further. It is noted that the MDD of each lime-bagasse fibresoil mixture was obviously lower than that of the bagasse fibre reinforced soils without lime treatment. The MDD decrease of lime treated soils with bagasse fibre might be attributed to the lower specific gravity of bagasse fibre together with the flocculation and agglomeration because of cation exchange processes between clay particles and lime that changed the soil particles to be coarser particles. As mentioned earlier, the formation of the coarser particles occupying the larger spaces in the soil matrix, increased the void volume and hence reduced the dry density of the treated soil mixtures. In addition, tiny air gaps trapped into fibre surface could be another possible reason that explains the reduction of the MDD of lime-fibre-mixtures. An increase in bagasse fibre content led to the increase in the tiny air gaps and hence reduced the MDD of stabilised soil composite. Results of this investigation are consistent with other researcher observations (Ayeldeen \& Kitazume 2017; Kinuthia et al. 1999).

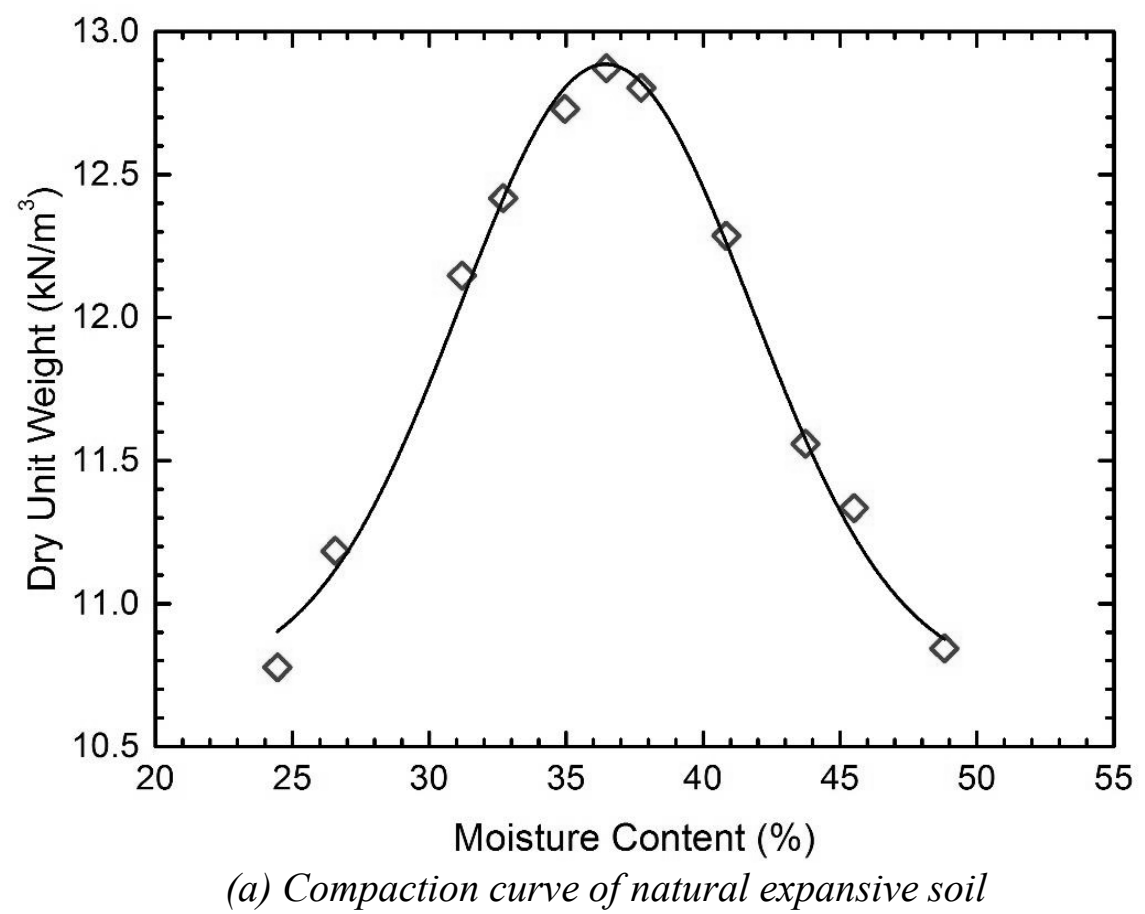




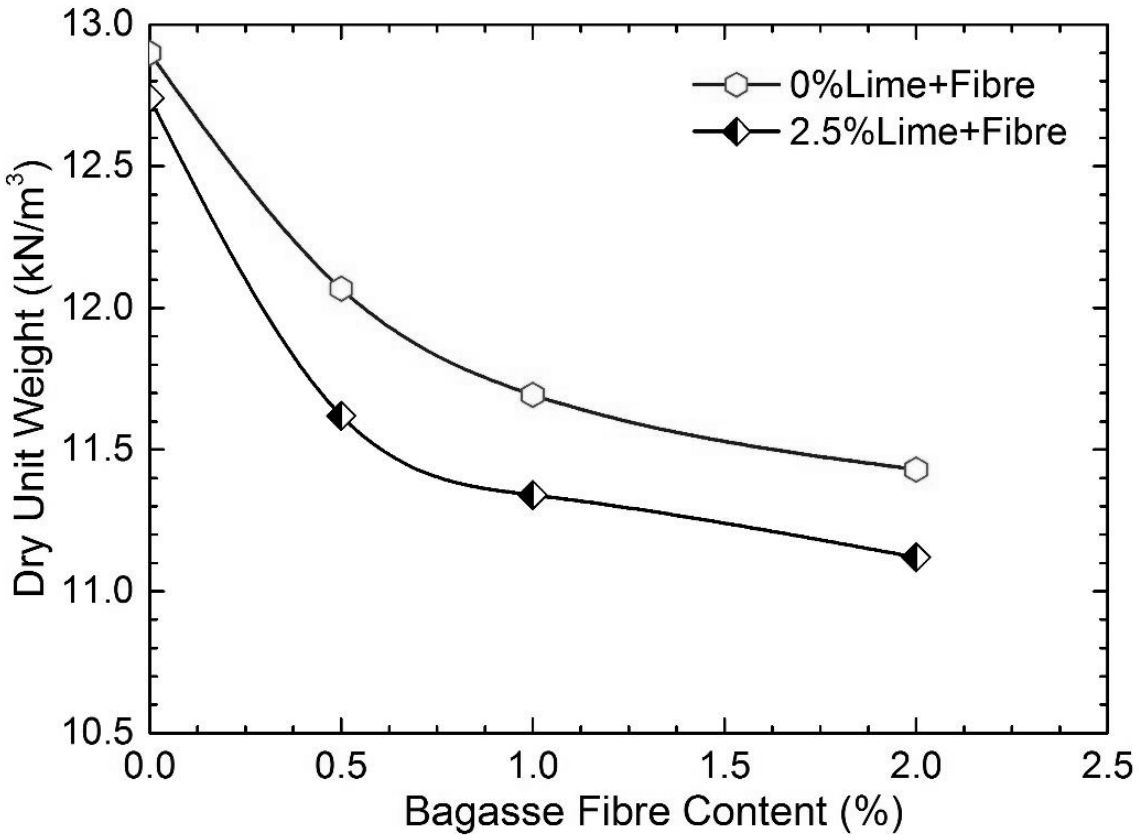

(b) Compaction curves of lime treated expansive soil with bagasse fibre reinforcement

\section{FIG. 5. Compaction curves of expansive soil reinforced with different contents of bagasse fibre and hydrated lime}

\section{Effects on the compression characteristics}

The previous investigation by the authors revealed that for only bagasse fibre reinforcement of expansive soil, when bagasse fibre content increased from $0 \%$ to $2 \%$, the unconfined compressive strength, the California bearing capacity, and the linear shrinkage of reinforced soils, compared to non-reinforced soil, were found to significantly improve by approximately $40 \%, 34 \%$ and $40 \%$, respectively. However, the swelling potential was observed to reduce by a great amount of $48 \%$ as bagasse fibre content increased from $0 \%$ to $1 \%$ and this was followed a small increase in the swelling potential as an additional increase in bagasse fibre exceeded $1 \%$. These findings confirmed the effectiveness of adding bagasse fibre alone in improving the shrink-swell behaviour and the other mechanical characteristics of reinforced expansive soils. Further details of the experimental investigations could be found in Dang et al. (2016b) and Dang et al. (2017c).

In this study, a series of Oedometer tests was undertaken on expansive soils treated with combinations of a fixed lime content with different contents of bagasse fibre after 3 days of curing and 4 days soaking (so-called 7 days of curing). As it can be found in FIG. 6 that when the bagasse fibre content was varied from $0 \%$ to $2 \%$, only $2.5 \%$ hydrated lime were added to bagasse fibre-soil mixtures to study the effect of adding bagasse fibre on the compressible property of lime treated expansive soil. Moreover, to have a better comparison of the compressibility between untreated soil and lime treated soils with bagasse fibre reinforcement, the test results obtained from untreated soil sample is also 
depicted in FIG. 6. Observation of the experimental results in FIG. 6 reveals that adding bagasse fibre into lime treated soil mixtures was found to reduce the compression characteristics of reinforced soils as bagasse fibre content increased from $0 \%$ to $1 \%$. Subsequently, the compressibility of lime treated soils reinforced with bagasse fibre indicated a slight increase when the addition of bagasse fibre exceeded $1 \%$. When compared with the compression curves of untreated soil and $2.5 \%$ lime treated soil, the lower slope reduction of the virgin compression curves was found for soil samples treated with $2.5 \%$ lime in combination of bagasse fibre reinforcement. Referring to FIG. 6 , the combination $2.5 \%$ lime and $1 \%$ bagasse fibre caused the most notable improvement in the virgin curve of reinforced soils.

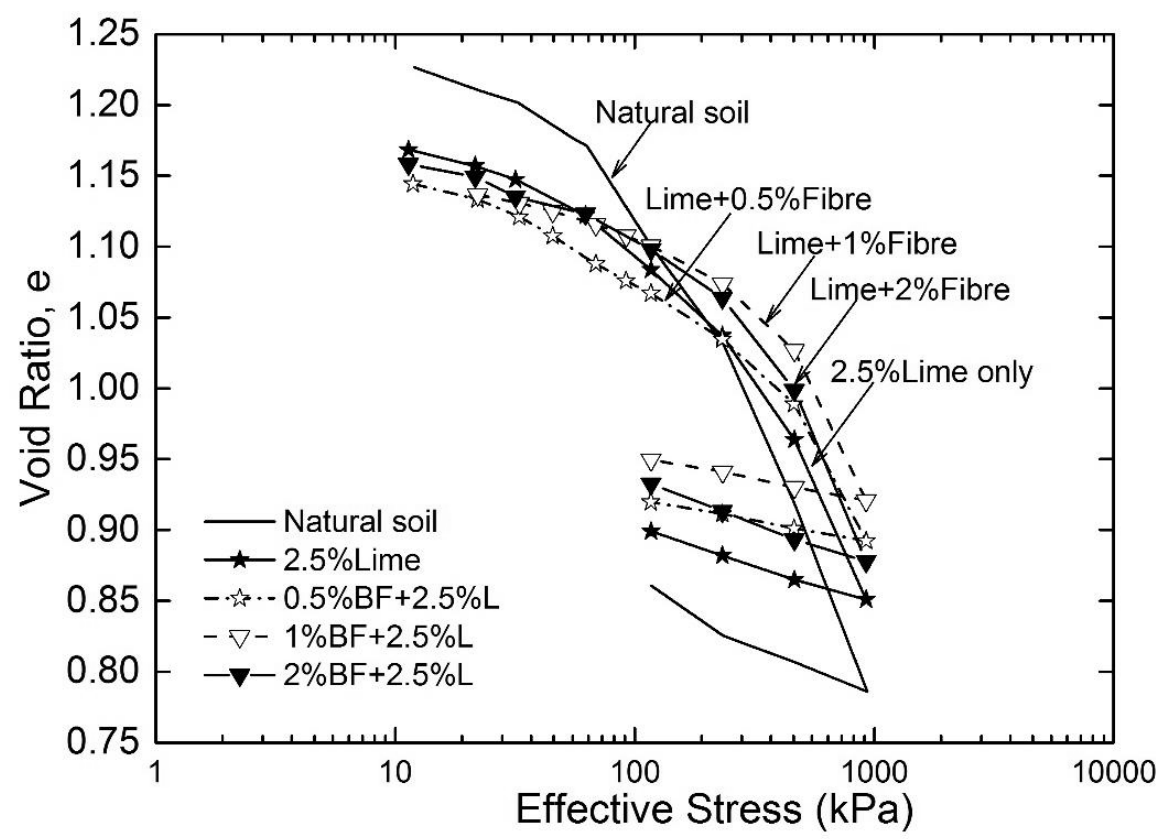

FIG. 6. Compression curves of expansive soil reinforced with different contents of bagasse fibre and $2.5 \%$ lime

The compressibility decrease of expansive soil stabilised with lime-bagasse fibre combination could be attributed to replacement of exchangeable ions on the clay surface with calcium ions in lime as a result of cation exchange. This phenomenon transformed the clay particles in the lime-soil matrix to become coarser, stronger and less plastic, which consequently promoted the improvement in the compressibility of treated soils. In addition, when bagasse fibre was introduced into the lime-soil mixture, interactions between bagasse fibre surface and lime-soil matrix with curing time might contribute to additional improvement in the compressible property of stabilised soils. As expected, when bagasse fibre content increased, the fibre surface area that was exposed to soil matrix also increased, which facilitated the better resistance to the compression pressure. However, the excessive addition of fibre bagasse content into lime-soil mixtures was about to increase the compressibility of stabilised soils to a certain extent due to the relatively high compressibility of natural bagasse fibre compared with soil particles. 
The influence of bagasse fibre reinforcement on the preconsolidation pressure of lime treated expansive soil is illustrated in FIG. 7. It is noted that the preconsolidation pressures of $2.5 \%$ lime treated soils with various bagasse fibre contents were deprived from FIG. 6 using a proposed method of Boone (2010). Observation of the preconsolidation pressures presented in FIG. 7 notes that the increase in bagasse fibre content from $0 \%$ to $1 \%$ to reinforce soils with $2.5 \%$ lime resulted in the corresponding increase in the pre-consolidation pressure from $165 \mathrm{kPa}$ to around $240 \mathrm{kPa}$ (approximately $45 \%$ improvement). When additional increase in bagasse fibre content beyond $1 \%$ exhibited a marginal decrease in the preconsolidation pressure of reinforced soils to a certain value of $215 \mathrm{kPa}$. However, by comparing with untreated soil and only $2.5 \%$ lime treated soils, the preconsolidation pressure of $2.5 \%$ lime treated soil with $2 \%$ bagasse fibre reinforcement significantly increased by $38 \%$ and $30 \%$, respectively. This behaviour reveals that bagasse fibre reinforcement was very effective in improving the preconsolidation pressure of lime-soil mixture, whereas an excessive inclusion of bagasse fibre content exceeded $1 \%$ tented to reduce its positive impact on the improvement in the preconsolidation pressure of reinforced soils with lime.

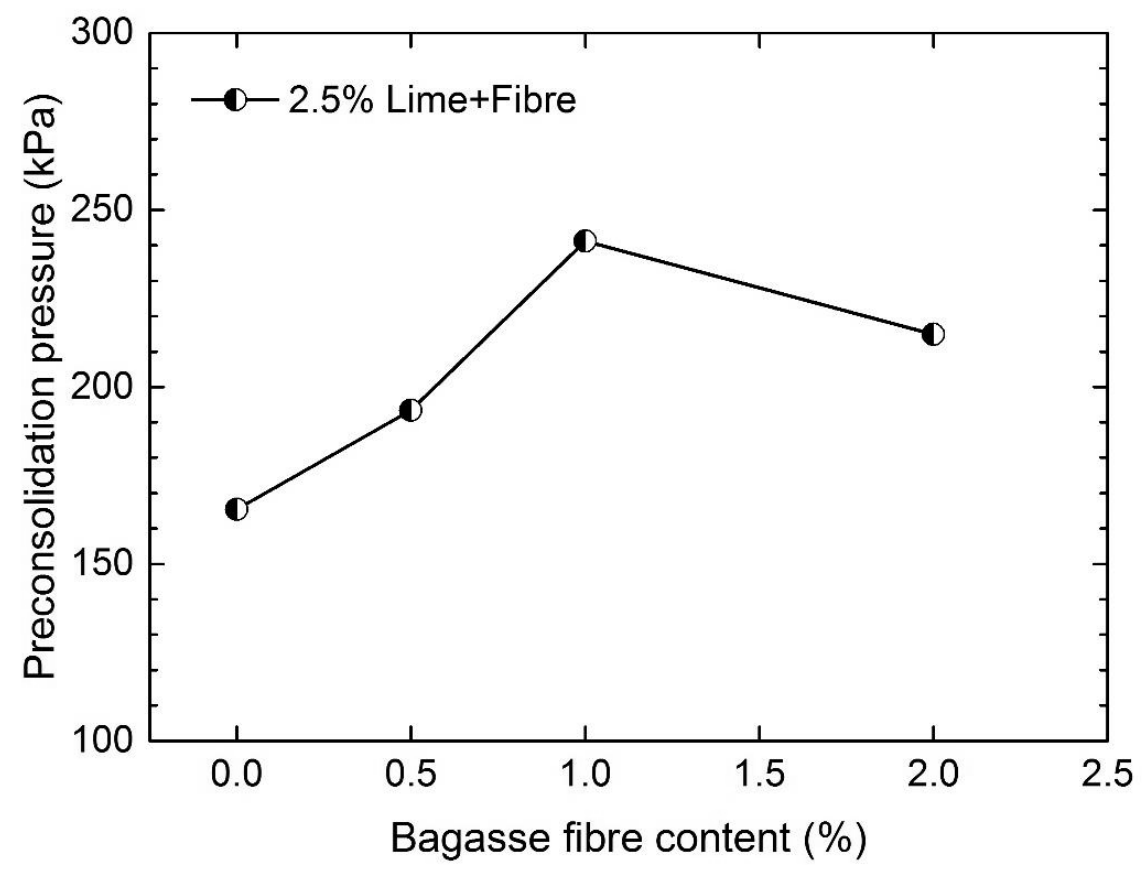

FIG. 7. Variation of preconsolidation pressure of expansive soil reinforced with various contents of bagasse fibre and $2.5 \%$ lime

FIG. 8 indicates the influence of bagasse fibre reinforcement on the variation of compression index $(\mathrm{Cc})$ and swelling index $(\mathrm{Cs})$ of $2.5 \%$ lime-soil mixtures after curing and soaking for 7 days. It can be noted that $\mathrm{Cc}$ is defined as the slope of the straight line portion (virgin compression portion) of the effective stress-void ratio curve, meanwhile $\mathrm{Cs}$ is the slope of the unloading compression curve. As can be seen in FIG. 8, the value of $\mathrm{Cc}$ appeared to reduce with increasing bagasse fibre inclusion from $0 \%$ to $1 \%$. 
However, an increasing trend of the compression index was observed when the bagasse fibre inclusion into the lime-soil mixture increased beyond 1\%. A similar behaviour can be found the swelling index of lime treated soils with bagasse fibre reinforcement as bagasse fibre content increased up to $2 \%$. As observed in FIG. 8, the change of Cc was more pronounced than the Cs variation of reinforced soils with lime stabilisation. The reduction of both the $\mathrm{Cc}$ and $\mathrm{Cs}$ indices confirms that the addition of bagasse fibre can effectively reduce the compressibility of lime treated soils. As noted earlier, the improvement of lime treated soils reinforced with bagasse fibre might be due to the interlocking mechanism and interaction between lime-soil matrix and bagasse fibre surface that play an important role in improving the mechanical properties of reinforced soils. As bagasse fibre content increased to a certain amount, the lime-soil mixtures with bagasse fibre reinforcement would promote the better resistance to the applied compression pressure, and consequently facilitate the lower compressibility of reinforced soils.

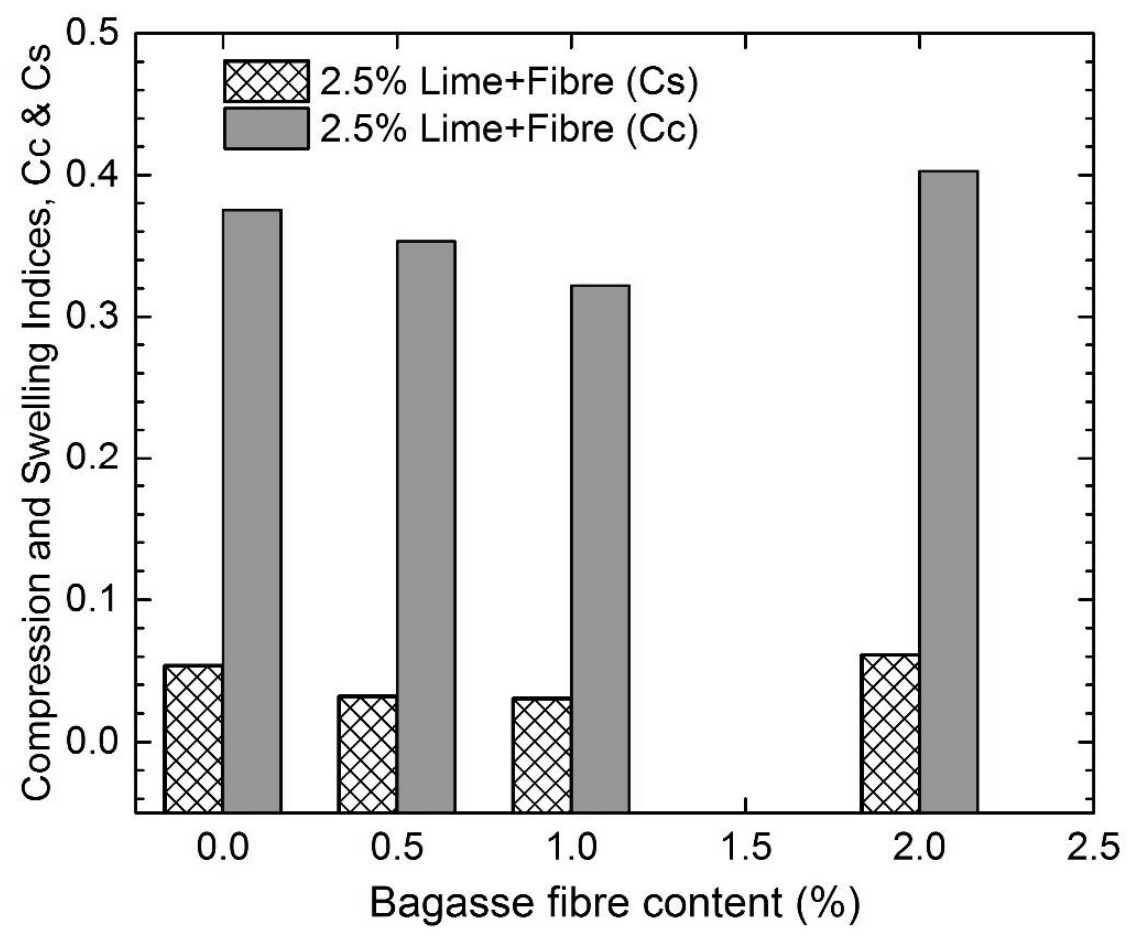

FIG. 8. Variations of compression and swelling indices of expansive soil reinforced with various contents of bagasse fibre and $2.5 \%$ lime

\section{CONCLUSIONS}

This paper shows an experimental investigation, conducted on expansive soils stabilised with different contents of lime and bagasse fibre reinforcement, in order to evaluate the compaction and compressibility characteristics of stabilised soils. The key findings of this investigation are summarised as follows:

- In comparison with untreated soil, the maximum dry density (MDD) of soils reinforced with only bagasse fibre was found to gradually decrease with increasing the bagasse fibre content from $0 \%$ to $2 \%$. With the addition of hydrated lime into 
the bagasse fibre-soil mixtures, the MDD of combined hydrated lime-bagasse fibre reinforced soils decreased further.

- From the one-dimensional consolidation test results, it is concluded that the addition of bagasse fibre into soils stabilised with lime was found to result in a remarkable influence on the compressible properties of reinforced soils. The compression curve, the compression and swelling indices reduced, meanwhile the preconsolidation pressure of stabilised soils improved, as bagasse fibre content increased from $0 \%$ to $1 \%$. However, the improvement was observed to reduce when bagasse fibre inclusion increased further to $2 \%$. This finding corroborates that adding a certain amount of bagasse fibre into lime-soil mixtures was proved to promote the most effective improvement in the compressibility characteristics of treated soil.

- This investigation indicated that the utilisation of hydrated lime-bagasse fibre combination for expansive soil treatment could highly be effective in not only improving the geotechnical properties of expansive soil but also minimising the environmental impacts of an agricultural waste by-product of bagasse fibre. This study also revealed that bagasse fibre reinforcement had the potential use as a recycled, environmentally friendly and cost-effective additive in combination of with lime for sustainable civil infrastructure construction development because of reducing the consumption of conventional stabilisers such as lime or cement, commonly adopted in treatment of expansive soil.

\section{ACKNOWLEDGMENTS}

The results presented in this paper are part of an ongoing research at University of Technology Sydney (UTS) supported by the Australian Technology Network (ATN), Arup Pty Ltd, Queensland Department of Transport and Main Roads (TMR), ARRB Group Ltd and Australian Sugar Milling Council (ASMC). The authors gratefully acknowledge their support.

\section{REFERENCES}

Anggraini, V., Asadi, A., Farzadnia, N., Jahangirian, H. \& Huat, B. 2016, 'Reinforcement Benefits of Nanomodified Coir Fiber in Lime-Treated Marine Clay', Journal of Materials in Civil Engineering, vol. 0, no. 0, p. 06016005.

AS 1993, Geotechnical Site Investigations, AS 1726-1993, Standards Australia, Sydney, Australia.

AS 1998, Determination of the one-dimensional consolidation properties of a soil Standard method, AS 1289.6.6.1-1998, Standards Australia, Sydney, Australia.

AS 2017, Determination of the dry density/moisture content relation of a soil using standard compactive effort, AS 1289.5.1.1:2017, Standards Australia, Sydney, Australia.

Ayeldeen, M. \& Kitazume, M. 2017, 'Using fiber and liquid polymer to improve the behaviour of cement-stabilized soft clay', Geotextiles and Geomembranes, vol. 45, no. 6 , pp. 592-602.

Bell, F.G. 1996, 'Lime stabilization of clay minerals and soils', Engineering Geology, vol. 42, no. 4, pp. 223-37. 
Boone, S.J. 2010, 'A critical reappraisal of "preconsolidation pressure" interpretations using the oedometer test', Canadian Geotechnical Journal, vol. 47, no. 3, pp. 28196.

Chen, Q. \& Indraratna, B. 2014, 'Shear behaviour of sandy silt treated with lignosulfonate', Canadian Geotechnical Journal, vol. 52, no. 8, pp. 1180-5.

Dang, L.C. 2018, 'Enhancing the Engineering properties of Expansive Soil Using Bagasse Ash, Bagasse Fibre and Hydrated Lime', Ph.D. thesis, University of Technology Sydney.

Dang, L.C., Dang, C., Fatahi, B. \& Khabbaz, H. 2016a, 'Numerical Assessment of Fibre Inclusion in a Load Transfer Platform for Pile-Supported Embankments over Soft Soil', Geo-China 2016, eds D. Chen, J. Lee \& W.J. Steyn, vol. GSP 266, ASCE, pp. 148-55.

Dang, L.C., Dang, C.C. \& Khabbaz, H. 2017a, 'Behaviour of Columns and Fibre Reinforced Load Transfer Platform Supported Embankments Built on Soft Soil', the $15^{\text {th }}$ International Conference of the International Association for Computer Methods and Advances in Geomechanics, Wuhan, China.

Dang, L.C., Dang, C.C. \& Khabbaz, H. 2018a, 'Modelling of columns and fibre reinforced load transfer platform supported embankments', Ground Improvement (under review).

Dang, L.C., Dang, C.C. \& Khabbaz, H. 2018b, 'Numerical Analysis on the Performance of Fibre Reinforced Load Transfer Platform and Deep Mixing Columns Supported Embankments', in M. Bouassida \& M.A. Meguid (eds), Ground Improvement and Earth Structures, Springer, Cham, pp. 157-69.

Dang, L.C., Dang, C.C. \& Khabbaz, H. 2018c, 'A Parametric Study of Deep Mixing Columns and Fibre Reinforced Load Transfer Platform Supported Embankments', Advances in Foundation and Ground Improvement Techniques, Springer, Cham.

Dang, L.C., Fatahi, B. \& Khabbaz, H. 2016b, 'Behaviour of Expansive Soils Stabilized with Hydrated Lime and Bagasse Fibres', Procedia Engineering, vol. 143, pp. 65865.

Dang, L.C., Hasan, H., Fatahi, B., Jones, R. \& Khabbaz, H. 2015a, 'Effects of bagasse ash and hydrated lime addition on engineering properties of expansive soil', GEOMATE 2015, Osaka, Japan, pp. 90-5.

Dang, L.C., Hasan, H., Fatahi, B., Jones, R. \& Khabbaz, H. 2016c, 'Enhancing the Engineering Properties of Expansive Soil Using Bagasse Ash and Hydrated Lime', International Journal of GEOMATE, vol. 11, no. 25, pp. 2447-54.

Dang, L.C., Hasan, H., Fatahi, B. \& Khabbaz, H. 2015b, 'Influence of Bagasse Ash and Hydrated Lime on Strength and Mechanical Behaviour of Stabilised Expansive Soil', GEOQuébec 2015, Québec City, Canada.

Dang, L.C. \& Khabbaz, H. 2018a, 'Assessment of the geotechnical and microstructural characteristics of lime stabilised expansive soil with bagasse ash', GeoEdmonton 2018, Alberta, Canada.

Dang, L.C. \& Khabbaz, H. 2018b, 'Enhancing the Strength Characteristics of Expansive Soil Using Bagasse Fibre', Springer Series in Geomechanics and Geoengineering, Springer, Cham.

Dang, L.C. \& Khabbaz, H. 2018c, 'Shear strength behaviour of bagasse fibre reinforced expansive soil', IACGE2018, vol. Geotechnical Special Publications, ASCE, 
Chongqing, China.

Dang, L.C., Khabbaz, H. \& Fatahi, B. 2017b, 'Evaluation of swelling behaviour and soil water characteristic curve of bagasse fibre and lime stabilised expansive soil', PanAm-UNSAT 2017, ASCE, Texas, USA.

Dang, L.C., Khabbaz, H. \& Fatahi, B. 2017c, 'An experimental study on engineering behaviour of lime and bagasse fibre reinforced expansive soils', $19^{\text {th }}$ ICSMGE, Seoul, Republic of Korea, pp. 2497-500.

Fatahi, B. \& Khabbaz, H. 2013, 'Influence of fly ash and quicklime addition on behaviour of municipal solid wastes', Journal of Soils and Sediments, vol. 13, no. 7, pp. 1201-12.

Fatahi, B. \& Khabbaz, H. 2015, 'Influence of Chemical Stabilisation on Permeability of Municipal Solid Wastes', Geotechnical and Geological Engineering, vol. 33, no. 3, pp. 455-66.

Fatahi, B., Khabbaz, H. \& Fatahi, B. 2012, 'Mechanical characteristics of soft clay treated with fibre and cement', Geosynthetics International, vol. 19, pp. 252-62.

Jones, L.D. \& Jefferson, I. 2012, 'Expansive soils', ICE manual of geotechnical engineering, ICE Publishing, London, pp. 413-41.

Kampala, A. \& Horpibulsuk, S. 2013, 'Engineering Properties of Silty Clay Stabilized with Calcium Carbide Residue', Journal of Materials in Civil Engineering, vol. 25, no. 5, pp. 632-44.

Kinuthia, J.M., Wild, S. \& Jones, G.I. 1999, 'Effects of monovalent and divalent metal sulphates on consistency and compaction of lime-stabilised kaolinite', Applied Clay Science, vol. 14, no. 1, pp. 27-45.

Mohamed, A.E.M.K. 2013, 'Improvement of swelling clay properties using hay fibers', Construction and Building Materials, vol. 38, pp. 242-7.

Viswanadham, B.V.S., Phanikumar, B.R. \& Mukherjeeb, R.V. 2009, 'Swelling behaviour of a geofiber-reinforced expansive soil', Geotextiles and Geomembranes. 